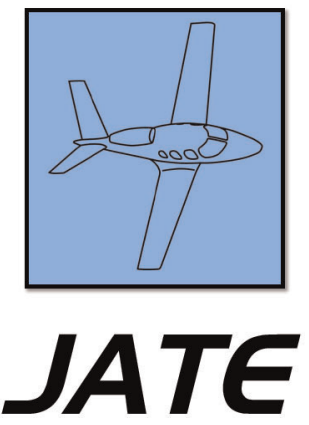

Journal of Aviation Technology and Engineering 3:1 (2013) 9-16

\title{
Measuring Intensity of Laser Light Penetrating Flight Decks in Laser Illuminations
}

\author{
Randal J. DeMik, Stanley L. Harriman, Ryan S. Phillips, Charles Crowder, Jennifer A. Pfeifer, \\ Shane F. McHugh, Steven J. Foster, Elizabeth R. De Waard, Michael Streit, \\ Richard B. Antoniolli, Ernest W. Knight, David S. York, and Jacob Luedtke
}

Lewis University

\begin{abstract}
Since 2005, reported laser attacks from people on the ground directed towards arriving and departing aircraft have increased over $300 \%$. A laser aimed at the windshield of an aircraft startles a pilot and may cause injury. This study determined empirical evidence of laser intensity in the flight deck and the potential for harm to the human eye at various distances. Results of this study revealed that relatively low-powered lasers had measured intensity levels through cockpit windshields at the 200 and 500 feet distances that may cause damage to crewmembers' eyes according to standards established by the federal government. At longer distances of 1000, 1500, and 2000 feet, these same lasers did not reveal measured intensities at levels to cause damage to crewmembers' eyes; however, they were considered as having potentially distracting visual effects in flight that were further categorized as temporary flash blindness, glare or disruption, and distraction or startle.
\end{abstract}

Keywords: laser, illumination, aviation, aircraft, hazards

\section{About the Authors}

Randal J. DeMik is an associate professor in Aviation and Transportation Studies at Lewis University. He earned his Ph.D. in technology management form Indiana State University. Dr. DeMik served as captain and line check airman with United Airlines and is a current FAA certified flight instructor.

Stanley L. Harriman is an assistant professor in Aviation and Transportation Studies at Lewis University. He earned his Ph.D. in aviation safety and training from Purdue University. He is a current FAA certified flight instructor and airframe/power plant mechanic.

Ryan S. Phillips is an assistant professor in Aviation and Transportation Studies at Lewis University. He earned his Ed.D. from University of South Dakota in adult and higher education. He is a current FAA gold seal certified flight instructor.

Charles Crowder is an associate professor in the Physics Department at Lewis University. He earned his Ph.D. from the University of MissouriColumbia.

Jennifer A. Pfeifer, Shane F. McHugh, Steven J. Foster, Richard B. Antoniolli, David S. York, and Jacob Luedtke are graduate students in the Aviation and Transportation Studies master's program at Lewis University.

Elizabeth R. De Waard, Michael Streit, and Ernest W. Knight are undergraduate students in the Physics Department at Lewis University.

This research was sponsored, in part, by a grant from the Colonel Stephan S. and Lyla Doherty Center for Aviation and Health Research. 


\section{Introduction}

The safety record of aviation has never been better and continues to improve. The number of fatal airline accidents in 2011 is the lowest in the last decade (Ranter, 2011). While these safety achievements have contributed to a positive public opinion of aviation, there is always room for improvement.

Generally, aviation accidents have three basic causes: severe weather, mechanical malfunction, or human error (Stolzer, Halford, \& Goglia, 2010). Technological improvements in the manufacture of aircraft and safety devices introduced during the past two decades have reduced accidents such as controlled flight into terrain (CFIT), midair collisions, and wind shear (Hawkins, 1998). Industry experts increasingly believe that the biggest accident risks now tend to come from surface threats. Richard Healing, a former member of the National Transportation Safety Board, agrees that "runway events are much more likely to pose a major hazard than in-flight problems" (Pasztor, 2011, p. A3).

Another aviation hazard that has steadily become more common over the past several years is laser attacks on aircraft. For this study, the definition of a laser attack is both the intentional and unintentional use of a laser beam striking an aircraft windshield during any phase of flight or ground operation. Since the FAA began formally tracking laser event reports in 2005, the number of reports has increased from 300 to over 3,000 over a six year period (Sabota, 2011). Several factors are responsible for the reported increase including greater awareness, outreach to pilots to encourage reporting, the availability of inexpensive laser devices on the internet, stronger power levels that enable lasers to hit aircraft at higher altitudes, and the introduction of green lasers-which emit the most sensitive wavelength for the human eye (Sabota, 2011).

The highest risk with intentional laser targeting from the ground would be during visual conditions at night on a predictable flight path, such as an instrument approach to a busy airport (Steenblik, 2011). These conditions and phases of flight can be especially dangerous due to the low altitude of the aircraft, the higher workload of the pilot, and the ease with which an assailant can aim a laser. According to Randy Babbitt, former Administrator of the FAA, when a high-powered laser shines into the flight deck of an airplane or helicopter, it can temporarily blind a pilot and make it difficult to safely fly or land the aircraft (Leiser, 2011). Scott Wallace from Careflight explained that repercussions from laser attacks may involve pilots with damaged eyesight deemed permanently unsafe to fly for hire (Sabota, 2011).

To initially combat this criminal trend, the FAA recently launched a website to provide information on the dangers of laser incidents and to make it easier for pilots and witnesses to file reports (Leiser, 2011). In June 2011, the FAA began imposing fines of up to $\$ 11,000$ against people caught shining lasers at planes (Hawley, 2011). "No accidents have been attributed to the illumination of crewmembers by lasers, but given the sizeable number of reports and debilitating effects that can accompany such events, the potential does exist" (Nakagawara, Wood, \& Montgomery, 2010, p. 1). Other strategies to reduce laser attacks include educating the public regarding the risks of lasers to aviation safety, encouraging the reporting of malicious behavior, restricting the sale of certain laser devices to the general public, requiring manufacturers to attach warning labels on laser devices, using laser eye protection in the aviation environment, and deploying laser detection and recording systems on aircraft (Sabota, 2011).

Advancements in laser technology and the danger they pose have created the need for laser eye protection. Some measures have been implemented into the flight deck of aircraft. Laser eye protection in the form of filters that are placed in spectacles and visors alter the environment in which pilots must work and can cause problems (Svec, 2005). "One case involved aircrew wearing yellow visors attempting to land on an unusable portion of the runway, they were unable to see the large yellow ' $\mathrm{X}$ ' indicating the hazard" (Svec, 2005, p. 42). One possible mitigation method is for the pilot to wear a pair of protective eyewear that reflect specific laser wavelengths (Stewart, 2005). For a variety of reasons, many people don't want to wear glasses or visors. Some of these devices do not allow enough light to pass through to the eye, which is especially important during night flight, and some change color perception. In addition, they need special care and must be safely stored to prevent damage (Svec, 2005).

There may be several possible reasons why people direct lasers at aircraft. In some cases, perpetrators are trying to inflict harm; in other cases the acts are unintentional and individuals are unaware of the potential danger. In one case, a man who was arrested near St. Louis, Missouri, admitted that he was unaware that the laser beam illuminated the whole flight deck (Lengel, 2011). Patrick Murphy, executive director of the International Laser Display Association, believes that average citizens point lasers at aircraft for the following reasons (Steenblik, 2011):

1. The beam doesn't appear to reach the aircraft.

2. Users think the beam will hit the bottom of the aircraft.

3. They think only a small laser "spot" will strike the aircraft.

Malicious or unintended discharging of a laser or other device into the flight deck of any aircraft is a safety hazard regardless what the reason for such discharge may be.

\section{Statement of the Problem}

Since 2005, the number of laser events has increased by over 300\% (Nakagawara et al., 2010). Given the sizeable 
number of reports and potentially harmful effects that can accompany such events, this situation may lead to an increase in aircraft accidents. This review of literature was unable to uncover any published studies that have provided empirical evidence of the harmful effects of laser illumination to pilots through aircraft windshields. Therefore, researchers in this study measured the harmful effects of lasers similar to those directed at pilots flying aircraft in an effort to answer the following research questions:

1. What is the measured intensity of laser light penetrating the flight deck based on laser wavelength, laser power output, and range as the laser penetrates various aircraft windshields?

2. Do measured intensities exceed federally mandated eye safety tolerances established by the Center for Devices and Radiological Health (CDRH)?

\section{Methodology}

\section{Windshields}

The following aircraft windshields, which are representative of the most common flight operations to be targeted in laser events, will be used in this study: a jet windshield and a general aviation windshield. The jet windshield is approximately 1.25 inches thick and is comprised of layers of vinyl compound and glass. The general aviation windshield was approximately 0.125 inch thick Plexiglas.

\section{Lasers}

Three relatively low-powered lasers were selected to represent lasers readily available for public purchase. Lasers utilized were a green $532 \mathrm{~nm}$ (nanometer) $50 \mathrm{~mW}$ (milliwatt) diode pumped solid state laser, a red $633 \mathrm{~nm}$ high powered pointer laser on a taser gun sight, and a violet $405 \mathrm{~nm} 100 \mathrm{~mW}$ diode laser. The green laser is categorized as a very bright and diffraction limited (the beam diameter remains relatively small even after traveling a long distance) beam. This laser is considered the worst case scenario for a pilot. The red laser is not diffraction limited but is readily available for consumer purchase.

\section{Measures}

A Newport Optical Power Meter, high-performance model 1918R was used to measure the laser light intensity in milliwatts. A hand-held, post mounted detector model 918SL-OD3 was connected to the meter.

\section{Procedures}

Readings were collected at the former Frankfort Illinois Airport (LL40) which is closed to the public and privately owned. The airport had a $4203 \times 50$ foot level runway with an elevation of 778 feet. Lasers were set up at the west end of the runway on a portable industry-grade optical table aimed east. Testing began after sunset to reduce signal-tonoise ratio issues caused by the sun. Distances of 200, 500, 1000, 1500 and 2000 feet were marked on the runway using a digital measuring wheel. A $4 \times 4$ foot peg board screen was located at each marked distance and used to standardize data collection. Using the pegboard provided evenly spaced holes $(1 \times 1$ inch) to effectively measure beam area and more accurately place the Newport Optical Power Meter.

The trial procedure was as follows: the laser was aimed down the runway towards the pegboard screen through each windshield. Laser beam spot power was measured by positioning the hand-held detector flush and centered over several screen holes, creating a power intensity map. This procedure was repeated for each of the three lasers while measuring beam size and power at all ranges (see Table 1).

\section{Results}

The first research question was constructed to determine the measured intensity of laser light penetrating the flight deck based on laser wavelength and range as the laser hits various aircraft windshields. For each colored laser, outdoor measurements were taken at night using 200', 500', 1000', 1500', and 2000' distances. Each laser's measurements were then analyzed as described in the procedures section. Tables 2 through 4 report the measured maximum power per unit area $\left(\mathrm{mW} / \mathrm{cm}^{2}\right)$ of light through general aviation and jet windshield from each laser at specific ranges.

Although measurements through the jet windshield differed, the trends remained consistent with the general aviation results. As distance increased, measured power of the laser on the screen decreased (refer to Figure 1). A visual depiction of the CDRH Class Map for this measurement can be found in Figures 2 through 5 .

An additional characteristic to consider is not only the brightness of the laser light but also the size of the beam at

Table 1

Laser measurement procedures

\begin{tabular}{lllll}
\hline Distances (ft.) & \multicolumn{1}{c}{200} & 500 & 1000 & 1500 \\
\hline Laser & Red/Green/Violet & Red/Green/Violet & Red/Green/Violet & Red/Green/Violet \\
Windshields & None/GA/Jet & None/GA/Jet & None/GA/Jet & None/GA/Jet \\
\hline
\end{tabular}


Table 2

Green laser intensity and physiological effects

\begin{tabular}{|c|c|c|c|c|c|}
\hline \multicolumn{6}{|c|}{ Green Laser } \\
\hline Range (ft.) & $\begin{array}{l}\text { Approximate Beam } \\
\text { Diameter (in.) }\end{array}$ & $\begin{array}{c}\text { GA Max Power/Unit } \\
\text { Area }\left(\mathrm{mW} / \mathrm{cm}^{2}\right)\end{array}$ & $\begin{array}{c}\text { Jet Max Power/Unit } \\
\text { Area }\left(\mathrm{mW} / \mathrm{cm}^{2}\right)\end{array}$ & CDRH Class & FAA Visual Effects \\
\hline 200 & 3 & 3.57 & 2.94 & IIIA & Possible Eye Damage \\
\hline 500 & 5 & 0.75 & 0.62 & I & Possible Eye Damage \\
\hline 1000 & 14 & 0.14 & 0.11 & I & Possible Eye Damage \\
\hline 1500 & 18 & 0.062 & 0.051 & I & Possible Eye Damage \\
\hline 2000 & 36 & 0.023 & 0.019 & I & Temporary Flash Blindness \\
\hline
\end{tabular}

Table 3

Violet laser intensity and physiological effects

\begin{tabular}{|c|c|c|c|c|c|}
\hline \multicolumn{6}{|c|}{ Violet Laser } \\
\hline Range (ft.) & $\begin{array}{l}\text { Approximate Beam } \\
\text { Diameter (in.) }\end{array}$ & $\begin{array}{c}\text { GA Max Power/Unit } \\
\text { Area }\left(\mathrm{mW} / \mathrm{cm}^{2}\right)\end{array}$ & $\begin{array}{c}\text { Jet Max Power/Unit } \\
\text { Area }\left(\mathrm{mW} / \mathrm{cm}^{2}\right)\end{array}$ & CDRH Class & FAA Visual Effects \\
\hline 200 & $2 \times 4$ & 4.77 & 3.94 & IIIA & Possible Eye Damage \\
\hline 500 & $4 \times 7$ & 0.77 & 0.64 & I & Possible Eye Damage \\
\hline 1000 & $5 \times 36$ & 0.21 & 0.17 & $\mathrm{I}$ & Possible Eye Damage \\
\hline 1500 & $6 \times 54$ & 0.060 & 0.050 & $\mathrm{I}$ & Possible Eye Damage \\
\hline 2000 & Exceeds Target Dimensions & 0.015 & 0.012 & $\mathrm{I}$ & Temporary Flash Blindness \\
\hline
\end{tabular}

Table 4

Red laser intensity and physiological effects

\begin{tabular}{lcccc}
\hline & & Red Laser \\
\hline Range (ft.) & $\begin{array}{c}\text { Approximate Beam } \\
\text { Diameter (in.) }\end{array}$ & $\begin{array}{c}\text { GA Max Power/Unit } \\
\text { Area }\left(\mathrm{mW} / \mathrm{cm}^{2}\right)\end{array}$ & $\begin{array}{c}\text { Jet Max Power/Unit } \\
\text { Area }\left(\mathrm{mW} / \mathrm{cm}^{2}\right)\end{array}$ & $\begin{array}{c}\text { CDRH Class } \\
\text { FAA Visual Effects }\end{array}$ \\
\hline 500 & $1 \times 2$ & 0.45 & 0.38 & I \\
1000 & $3 \times 4$ & 0.069 & 0.057 & I \\
1500 & $4 \times 5$ & 0.021 & 0.018 & I \\
2000 & $8 \times 10$ & 0.0094 & 0.0078 & Tessible Eye Damage \\
\hline
\end{tabular}

the various distances. The beam size increased for all lasers as the distance increased (refer to Figure 5). The examination of the data reveals that at 1000 feet the violet and green lasers maintain more maximum power per unit area and their beams are noticeably larger than the red laser. It should be noted that this is largely a result of the lower power level of the red laser used in this study ${ }^{1}$.

The second research question was constructed to determine whether the measured intensities exceed CDRH eye safety requirements through each flight deck windshield. Table 5 outlines CDRH laser classifications. The examination of the data reveals eye damage would be possible at the 200 foot range for all three lasers and at the 500 foot range for the green and violet lasers tested in this study. It should be noted that a more powerful red laser with the power classification of the green and violet used in this study may also cause eye damage at the 500 foot range. At 1000 feet and greater there is no threat of permanent eye

\footnotetext{
${ }^{1} \mathrm{~A}$ red laser of high intensity $(50 \mathrm{~mW})$ was not made available in time for this study.
}

damage for the lasers tested in this study; however, there are still physiological effects associated with exposure to intense light. These effects, as defined by Murphy (2009), are distraction and startle, glare and disruption, and temporary flash blindness.

Murphy (2009) categorizes the first classification as distraction and startle (less than $0.5 \mathrm{uW} / \mathrm{cm}^{2}$ ) which is defined as "an unexpected laser or bright light that can distract the pilot during a nighttime landing or takeoff. He or she might not immediately realize what was happening. Also, the pilot may be worried that a brighter light or other threat would be coming" (p. 3). The second classification is glare and disruption $\left(0.5 \mathrm{uW} / \mathrm{cm}^{2}\right.$ to $\left.5.0 \mathrm{uW} / \mathrm{cm}^{2}\right)$. This category makes it difficult for the pilot to see the environment outside and night vision begins to dissipate. The final classification is temporary flash blindness $\left(5.0 \mathrm{uW} / \mathrm{cm}^{2}\right.$ to $\left.50 \mathrm{uW} / \mathrm{cm}^{2}\right)$ which is similar to a camera flash. The CDRH numbers were determined from the $\mathrm{CDRH}$ regulations assuming a $7 \mathrm{~mm}$ diameter aperture and a 0.25 second blink response time (human's natural blink reflex). 


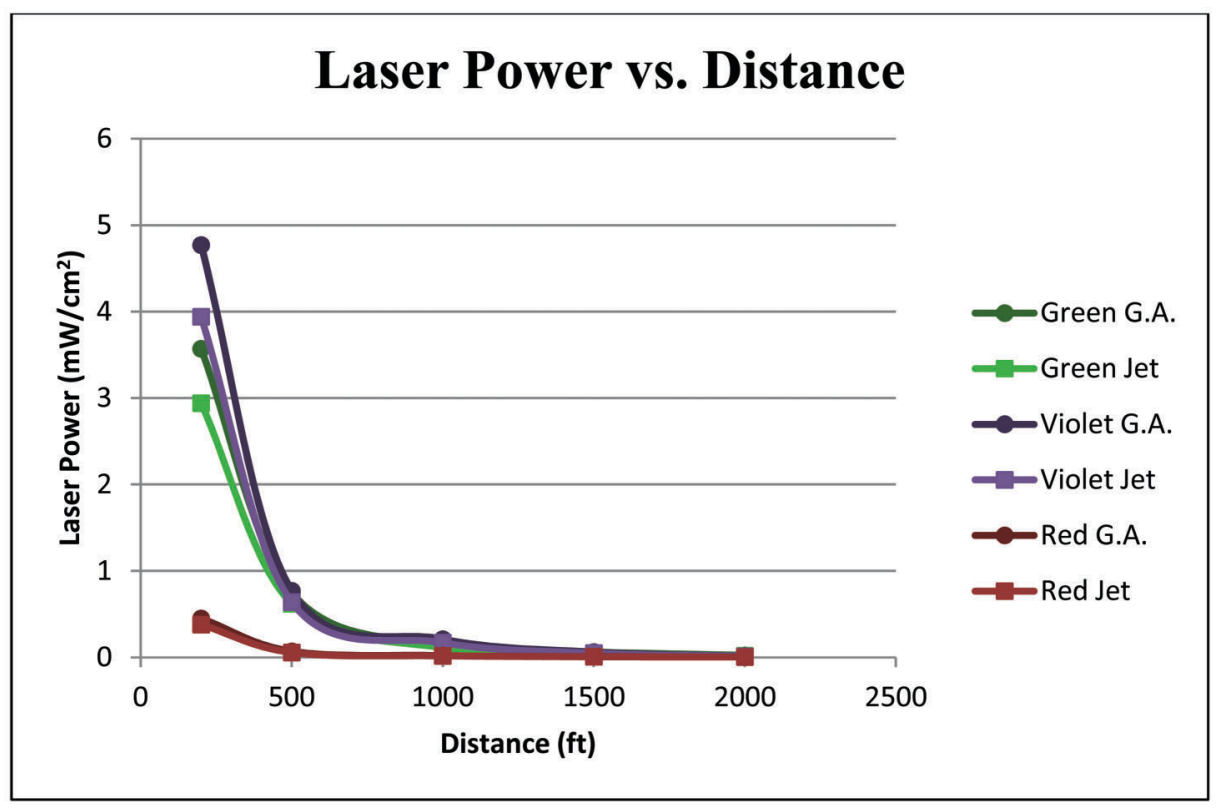

Figure 1. Measurement of power output for all lasers over distance.

\section{Discussion of the Results}

The purpose of this laser study was to provide empirical evidence that laser light penetrating the flight deck of an aircraft could cause retinal damage or create other safety hazards for pilots and the flying public. The specific intent of the study was to determine the laser light power and beam size at different critical distances from an aircraft. The results of this study indicated that the selected low power lasers measured at distances from $200^{\prime}$ to $2000^{\prime}$ would likely not cause permanent retinal damage. Data also illustrated that the laser light beams spread to a large

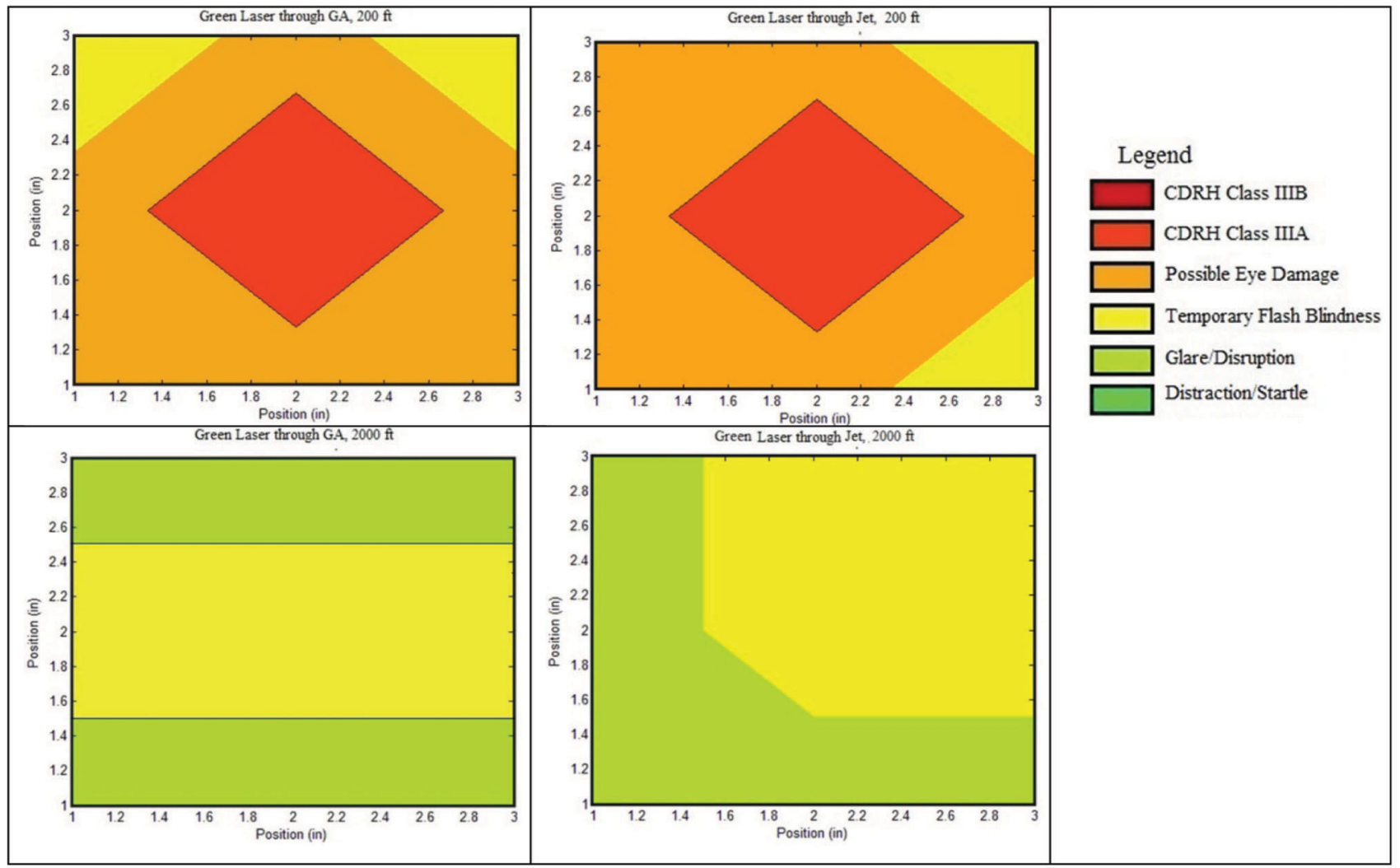

Figure 2. Classification map for the green laser. 


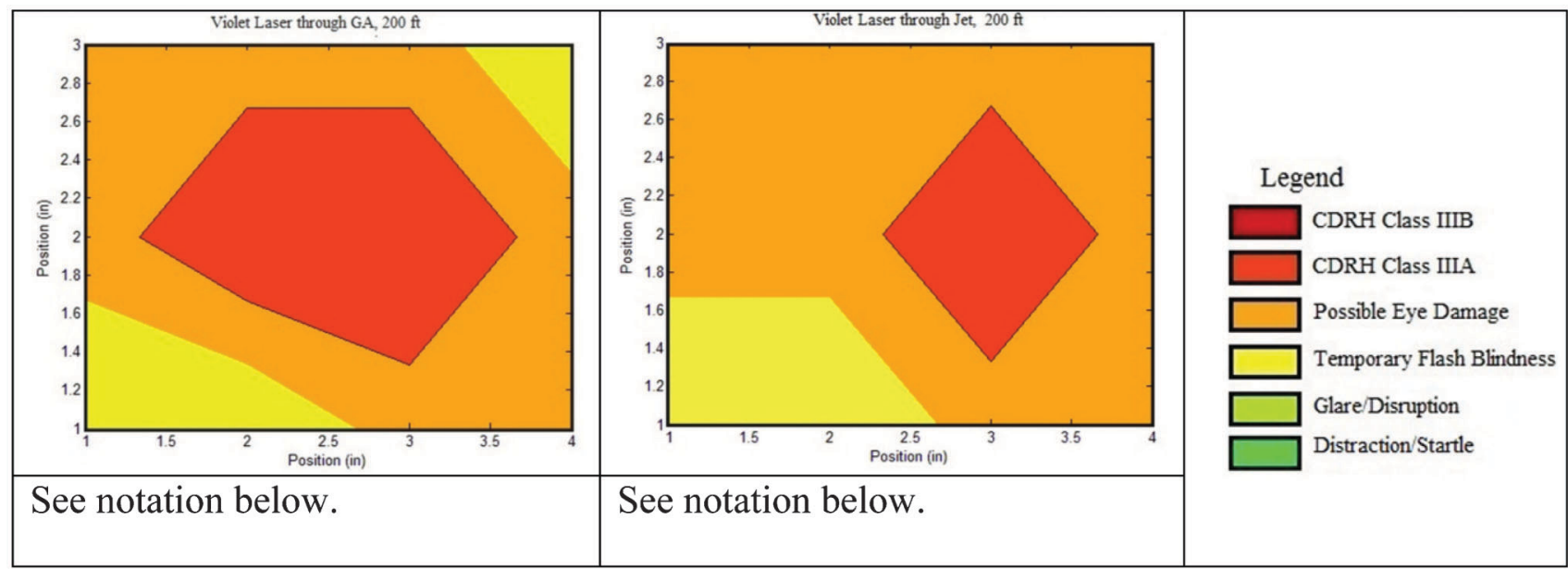

Figure 3. Classification map for the violet laser. Note: Only 200 feet readings are given. At 2,000 feet the beam size exceeded the measuring target.

enough size which would illuminate the flight deck of an aircraft with enough power to cause a pilot to be distracted. Distraction in this study is defined as temporary impairment of the pilot and further categorized as temporary flash blindness, glare/disruption or distraction/startle.

Potential eye damage readings occurred at closer distances of 200' and 500'. Green lasers are the focus of concern as $91 \%$ of laser strikes are with lasers of this color (Nakagawara et al., 2010). As darkness increases, the rods in the human eye become more active making the human eye more sensitive to green light even if the lasers are at similar output powers (Robinson \& Schmidt, 1984). As a result, the green laser beams appear to be brighter than other colors (Environmental Health \& Safety, 2012).

Regardless of the bright appearance of laser light, such as were used in this research, it is unlikely that permanent damage to a pilot's eyes could occur in a laser illumination event. This is partly due to a human's natural blink reflex which serves as sufficient retinal protection (Barkana \& Belkin, 2000). Studies show that after a laser eye injury,

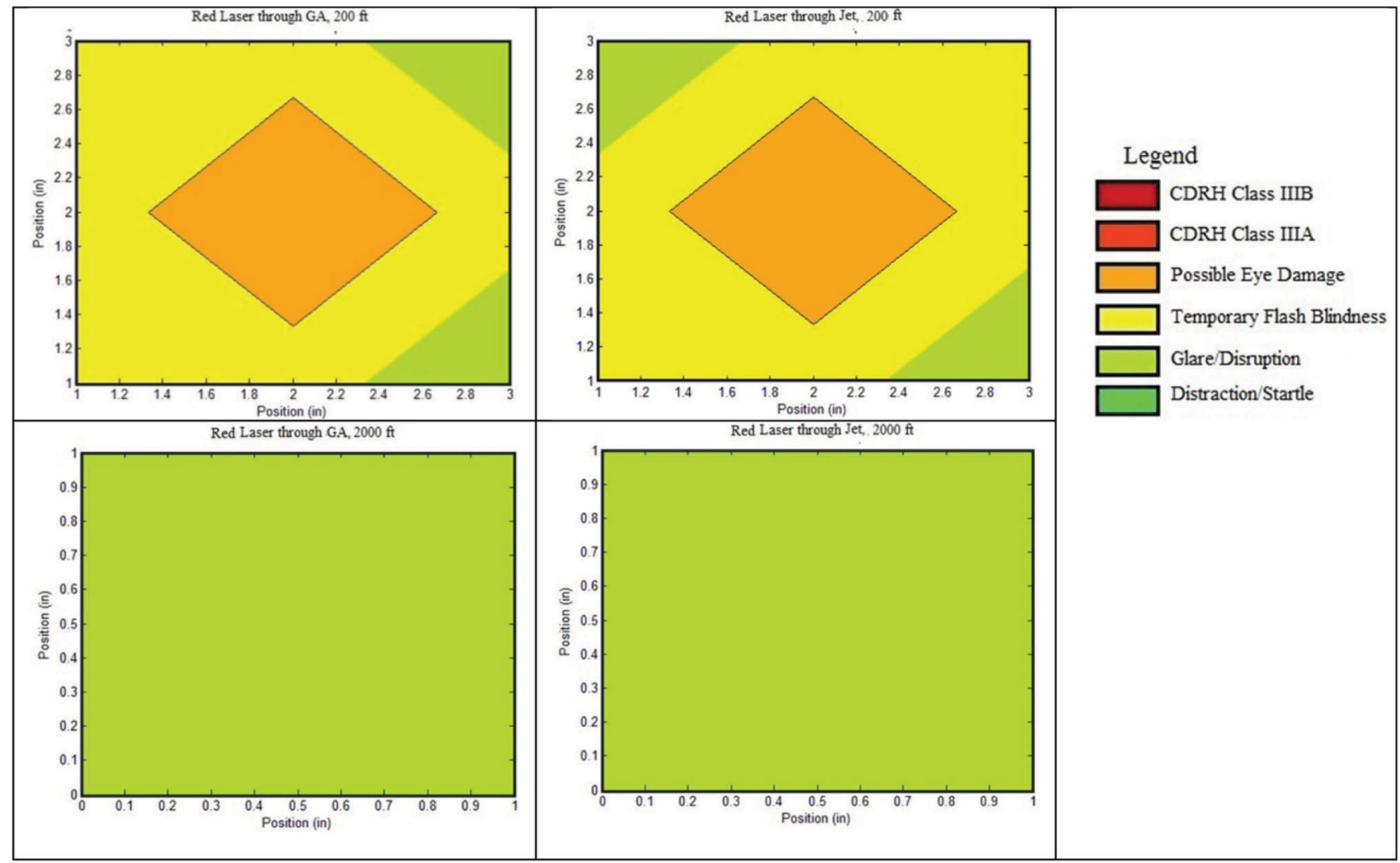

Figure 4. Classification map for the red laser. 


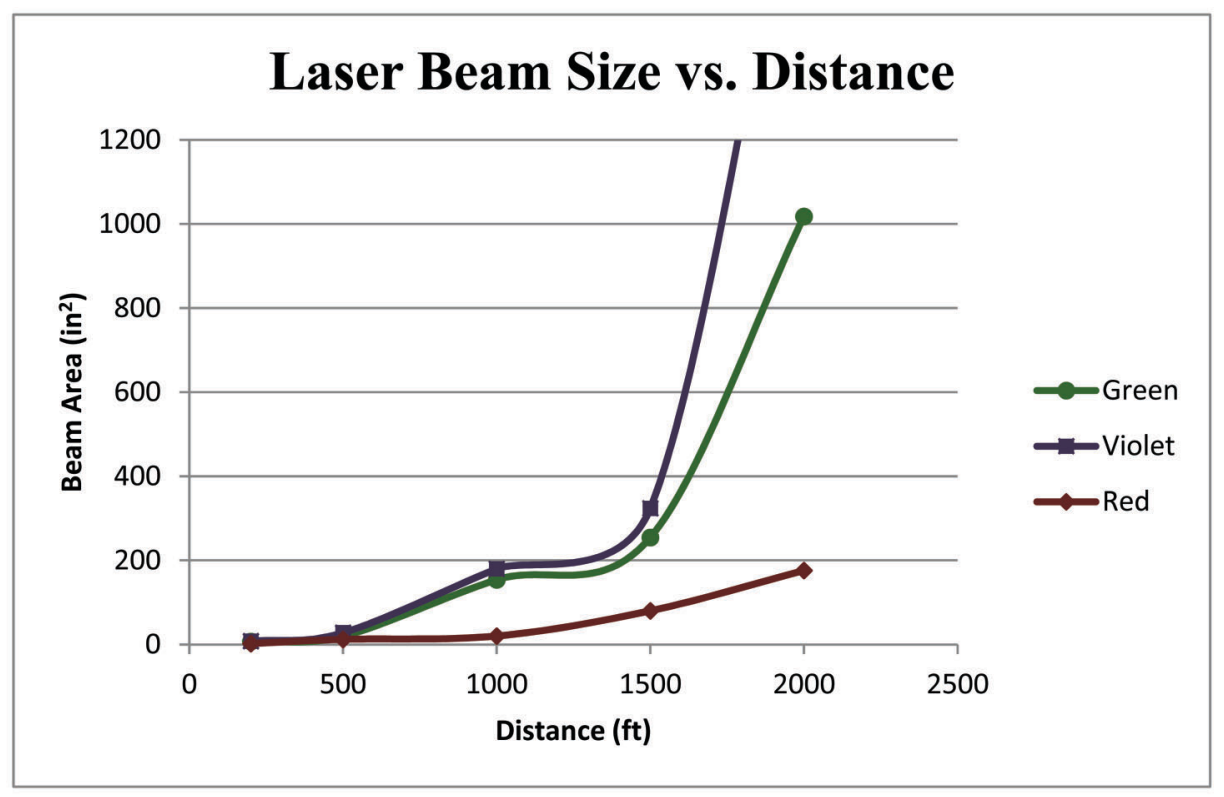

Figure 5. Measurement of beam size for all lasers over distance.

vision usually returns to normal within months (Baumal, 2011). Furthermore, Baumal (2011) posits that "it appears to be difficult to produce ocular injury with a laser pointer without deliberate inappropriate, prolonged, foveal exposure" (p. 1023).

Based on the results of this study, the potential risk to flight safety during illumination events is not necessarily eye damage; rather, it is the possibility of flight crews being distracted during critical phases of flight below 2000'. In a 2004 report by Nakagawara and Montgomery, the most common adverse visual effects reported by pilot test subjects immediately after each exposure to laser light were glare $(30.9 \%)$ and flash blindness $(30.9 \%)$, followed by after images (13.0\%). In approximately $75 \%$ of all responses, test subjects indicated they experienced adverse visual effects when exposed to any of the three levels of laser irradiance.

Since laser illumination events are on the rise, researchers from this study recommend organizations conducting flight operations produce flight crew procedures to mitigate visual effects (temporary flash blindness, glare/disruption, distrac-

Table 5

Threshold classifications for CDRH and Murphy

\begin{tabular}{lc}
\hline & Classification Thresholds* \\
\hline Classification & Min. Power/Unit Area $\left(\mathrm{mW} / \mathrm{cm}^{2}\right)$ \\
\hline CDRH Class IIIB & 13.0 \\
CDRH Class IIIA & 2.6 \\
CDRH Class I & no minimum \\
Possible Eye Damage & 0.05 \\
Temporary Flash Blindness & 0.005 \\
Glare/Disruption & $5.0 \times 10^{-5}$ \\
Distraction/Startle & no minimum \\
\hline
\end{tabular}

*Note: Derived from CDRH regulations. tion/startle) of laser illuminations exposure. According to Nakagawara et al. (2010), the following recommendations could serve as a guideline to develop specific procedures: have the non-flying pilot be prepared to take control of the aircraft; consider engaging autopilot to maintain flight path (if applicable); climb or turn away in order to use the fuselage of the aircraft to block the laser; inform air traffic control of last known location and direction of the beam; and increase the intensity of cockpit lighting.

In order to minimize damage to the eyes, Nakagawara et al. (2010) also suggest pilots should shield and avoid rubbing their eyes to prevent further injuries. For any visual symptoms that persist after landing, the pilot should be examined by a qualified physician.

\section{Recommendations for Future Research}

The effects of flight deck laser illumination demand further research. While regulations and laws have been implemented, laser illumination events continue to rise and the threat to flight crews is significant. Possible solutions include: improved laser eye protection such as glasses or goggles, protective coatings on windshields, sensory equipment to alert pilots, and continuing public education on the hazards of laser illumination as well as FAA efforts to increase penalties.

Another area for future research is the inclusion and comparison of higher powered lasers of multiple varieties (color, strength, etc.). Lasers of higher intensities have the potential to inflict greater optical damage at the ranges utilized in this study. While the researchers of this study used handheld lasers readily available to the public, future research should include lasers designed for commercial and industrial use. 


\section{References}

Barkana, Y., \& Belkin, M. (2000). Laser eye injuries. Survey of Ophthalmology, 44(6), 459-478. http://dx.doi.org/10.1016/S00396257(00)00112-0

Baumal, C. (2011). Light toxicity and laser burns. Free Medical Textbook. Retrieved from http://medtextfree.wordpress.com/2011/01/10/chapter142-light-toxicity-and-laser-burns/

Environmental Health \& Safety. (2012). Laser pointer safety factsheet. University of California - Irvine. Retrieved from http://www.ehs.uci. edu/programs/radiation/Laser\%20Pointer\%20Safety\%20Factsheet.pdf

Hawkins, F. H. (1998). Human factors in flight $\left(2^{\text {nd }}\right.$ ed). Brookfield, VT: Ashgate.

Hawley, C. (2011). Lasers aimed at 6 planes going to NYC's LaGuardia. Retrieved from http://news.yahoo.com/lasers-aimed-6-planes-goingnycs-laguardia-211534890.html

Leiser, K. (2011). Incidents of lasers vs. aircraft hit a record. St. Louis Post-Dispatch. Retrieved from http://www.stltoday.com/news/local/ metro/incidents-of-lasers-vs-aircraft-hit-a-record/article_3aa8aadcdf4c-5e0b-907e-efd1ce6e0936.html

Lengel, A. (2011). FBI says lasers pointed at aircraft nearly doubled in 2010. ticklethewire.com. Retrieved from http://www.ticklethewire. com/2011/09/27/fbi-says-lasers-pointed-at-aircraft-nearly-doubled-in2010/

Murphy, P. (2009). Lasers and aviation safety. International Laser Display Association. Retrieved from http://www.laserist.org/files/Lasers-andaviation-safety_2pt2.pdf
Nakagawara, V., \& Montgomery, R. (2004). The effects of laser illumination on operational and visual performance of pilots during final approach. Springfield, VA: Federal Aviation Administration.

Nakagawara, V., Wood, K., Montgomery, R. (2010). Laser hazards in navigable airspace. Retrieved from http://www.faa.gov/pilots/safety/ pilotsafetybrochures/media/laser_hazards_web.pdf

Pasztor, A. (2011). The new frontier in air safety: Skies are now so safe on U.S. flights that experts turn focus to 'surface threats'. Wall Street Journal, p. A3. Retrieved from http://online.wsj.com/article/ SB10001424052970203686204577113693683788110.html

Ranter, H. (2011). ASN releases preliminary airliner safety statistics 2011. Aviation Safety Network. Retrieved from http://aviation-safety.net/ news/newsitem.php?id $=2481$

Robinson, S. J., \& Schmidt, J. T. (1984). Fluorescent penetrant sensitivity and removability: What the eye can see, a fluorometer can measure. Materials Evaluation, 42(8), 1029-1034.

Sabota, M. (2011, December 12). FAA launches website for laser incident reports. Fort Worth Star-Telegram, B.

Steenblik, J. (2011). All I could see was green. Air Line Pilot, 80(10), 34-35.

Stewart, C. (2005). Weapons of mass casualties and terrorism response handbook. Sudbury, MA: Jones and Bartlett.

Stolzer, A., Halford, C., \& Goglia, J. (2010). Safety management systems in aviation. Burlington, VT: Ashgate.

Svec, L. (2005). The effect of spectrally selective filters on color perception and aviation performance (doctoral dissertation). Retrieved from ProQuest Digital Dissertations. (AAT 305429655) 